\title{
Infertility within the Lebanese population: beliefs and realities
}

\author{
Jean-Paul K. K. Sahakian ${ }^{\text {* }}$ (D, Elie El Helou², Jessica Azoury ${ }^{3}$, Laure Salameh ${ }^{4}$ Imad Abou Jaoude ${ }^{4}$ and \\ Ghassan Sleilaty $^{5}$
}

\begin{abstract}
Background: Infertility affects almost one in five couples but is still poorly understood by the general public. Although the socio-cultural aspect of infertility has already been covered in some countries, there is currently no study concerning the Lebanese population's view on this topic. This study aims to examine the knowledge and perception of the Lebanese population regarding infertility. The findings of this study could inform the creation of appropriate awareness campaigns aiming to rectify existing ideas based on myths and Lebanese folklore and establish a scientific understanding of infertility.

Results: Six hundred and nine participants were interviewed, and the responses recorded were statistically significant and correlated with $p$ values $<0.05$ with the participants' personal data, in particular their gender and academic level. Men were twice as likely as women to believe that couple infertility is a valid reason for a divorce or a second marriage. In addition, most men said that they would first consult a gynecologist in the event of couple infertility, which highlights the fact that the general population assumes the cause of infertility is of female origin, even though both sexes are frequently affected. In addition, men are twice as likely as women to refuse to live with an infertile spouse and the most educated respondents tend to be more aware and open to the idea of adopting a child or to use in vitro fertilization.
\end{abstract}

Conclusion: This study is the first to examine the socio-cultural beliefs and habits regarding infertility in Lebanon, with a focus on society's attribution of infertility to women. More studies are needed to understand how a personal experience of infertility can affect one's understanding and perceptions regarding infertility. Furthermore, Lebanese physicians should adopt a more multidisciplinary approach when managing couple infertility.

Keywords: Infertility, Cultural, Social, Questionnaire, Perception

\section{Background}

Infertility affects almost one in five couples [1] but is still poorly understood by the general population. It is defined as a disease caused by the inability to conceive a child after 12 months of regular sexual intercourse without the use of contraception [2]. Infertility can have psychological repercussions and often leads to marital problems. In fact, a meta-analysis showed that more than $35 \%$ of Iranian infertile couples suffered from

\footnotetext{
* Correspondence: Sahakian.jeanpaul@gmail.com

${ }^{1}$ Hôtel-Dieu de France Hospital, Faculty of Medicine, Saint-Joseph University, Beirut, Lebanon

Full list of author information is available at the end of the article
}

depression [3]. Moreover, women with primary infertility are significantly more depressed and anxious than fertile women [4].

Few studies have been conducted to assess a general population's knowledge and perceptions of infertility. However, there is currently no study of this kind concerning the Lebanese population. Lebanon's population is unique regarding its beliefs and socio-cultural habits, especially regarding a couple's fertility because of its geographical situation, being at the crossroads of the western and eastern worlds.

Infertility is often neglected, especially in Lebanon, where there is no specific law or regulation dedicated to

\section{Springer Open}

(๑) The Author(s). 2020 Open Access This article is licensed under a Creative Commons Attribution 4.0 International License, which permits use, sharing, adaptation, distribution and reproduction in any medium or format, as long as you give appropriate credit to the original author(s) and the source, provide a link to the Creative Commons licence, and indicate if changes were made. The images or other third party material in this article are included in the article's Creative Commons licence, unless indicated otherwise in a credit line to the material. If material is not included in the article's Creative Commons licence and your intended use is not permitted by statutory regulation or exceeds the permitted use, you will need to obtain permission directly from the copyright holder. To view a copy of this licence, visit http://creativecommons.org/licenses/by/4.0/. 
reproduction practices [5]. This study aims to examine the knowledge and perception of the Lebanese population regarding infertility. The findings of this study could inform the creation of appropriate awareness campaigns aiming to rectify existing ideas based on myths and Lebanese folklore and establish a scientific understanding of infertility. Using a survey, this work examines Lebanese people's perceptions regarding causes of infertility and their general knowledge regarding infertility solutions such as in vitro fertilization or adoption.

\section{Objectives of the study}

Primary: To assess the knowledge and perception of the Lebanese population regarding infertility and its consequences

Secondary: To assess the different opinions of study participants according to their age, sex, educational level, marital status, and profession

\section{Methods}

This is a cross-sectional study targeting the general Lebanese population. We initially designed a questionnaire inspired by previously published literature on infertility $[6,7]$. It was then reviewed and modified by two infertility specialists. This questionnaire is not an adaptation for any previous questionnaire and thus no validation step was required during the study.

Participants were asked about their personal information, demographics, and beliefs about infertility via a questionnaire distributed to our target population at Saint Joseph University, Hôtel Dieu de France Hospital, and infertility centers at Abou-Jaoude Hospital and Mont-Liban Hospital. The survey was distributed online as a Google form as well as in person in paper form over a period of 6 months, from August 2019 to January 2020. The questionnaire was written in French, English, and Arabic and included 29 items.

\section{Inclusion and exclusion criteria}

Our target population was made up of Lebanese people aged over 18 who agreed to participate in the study.

The research protocol was reviewed and approved by the ethics committee of Saint Joseph University and Hôtel-Dieu de France Hospital. All subjects had the right to withdraw from the study when they wished without giving any explanation or notice. The questionnaire was anonymous and guaranteed the confidentiality of the study participants.

All the data collected were coded for statistical analysis using the SPSS v22.0 computer program. The correlations between the different items were analyzed using Chi-square tests. Results were considered to be statistically significant when the $p$ value was less than 0.05 .

\section{Results}

\section{Demographic data}

Out of a total of 609 respondents, $65 \%$ are under the age of 26. Most people who completed the questionnaire are women (63.7\% compared to $36.3 \%$ men), have accomplished university studies (93.4\%), and do not have children (81.3\%) (cf. Table 1).

The majority of respondents to the questionnaire did not experience a period of infertility in their life (90.5\%) against a small proportion having experienced a period of infertility $(4.6 \%)$ or are still infertile (4.9\%) (cf. Table 2). The participants suffering from infertility did so for a period less than a year $(29.9 \%)$ or more than a year $(70.1 \%)$.

$52.7 \%$ of respondents think that, according to society, women are to blame when a couple is infertile against $3 \%$ for men (21.7\% chose "both", $22.7 \%$ chose "none").

Most respondents think that both the man and the woman should be investigated simultaneously during a case of infertility (78.5\%) against a lower proportion who thinks that the man or the woman should be investigated first (15.6\% and 5.9\% respectively).

The majority of respondents to the questionnaire would go for infertility treatment to a gynecologist (78.8\%) rather than a urologist (18.6\%) in the first place. To obtain a second opinion, more than half would go to a second gynecologist (53.4\%) rather than consulting a urologist (32.5\%). It is important to note that the

Table 1 Sociodemographic data of the respondents $(N=609)$

\begin{tabular}{llll}
\hline Demographic data & & $N$ & $\%$ \\
\hline Sex & Male & 221 & 36.30 \\
Fge & $18-22$ & 388 & 63.70 \\
& $23-26$ & 149 & 24.50 \\
& $27-32$ & 246 & 40.40 \\
& $33-44$ & 69 & 11.30 \\
Educational level & $45-75$ & 94 & 15.40 \\
& No school diploma & 3 & 8.40 \\
& Brevet & 11 & 0.50 \\
& Baccalaureate & 26 & 4.80 \\
& University studies & 569 & 93.40 \\
Marital status & Married & 167 & 27.40 \\
& In a relationship & 108 & 17.70 \\
& Bachelor & 322 & 52.90 \\
& Divorced & 9 & 1.50 \\
Number of children & Widowed & 3 & 0.50 \\
& 0 & 495 & 81.30 \\
& 1 & 38 & 6.20 \\
& 2 & 51 & 8.40 \\
& More than 2 & 25 & 4.10 \\
\hline
\end{tabular}


Table 2 distribution of respondents according to their experiencing of a period of infertility ( $N=609)$

\begin{tabular}{|c|c|c|c|c|c|c|}
\hline & & N & $\%$ & & $N$ & $\%$ \\
\hline \multirow[t]{9}{*}{ Have you ever had a period of infertility } & No & 551 & 90.50 & & & \\
\hline & Yes, but I am no longer infertile & 28 & 4.60 & Infertility of a male origin & 217 & 35.70 \\
\hline & & & & Infertility of a female origin & 87 & 14.30 \\
\hline & & & & Infertility of both male and female origin & 22 & 3.60 \\
\hline & & & & I do not know & 283 & 46.40 \\
\hline & Yes, I am still infertile & 30 & 4.90 & Infertility of a male origin & 122 & 20.00 \\
\hline & & & & Infertility of a female origin & 81 & 13.30 \\
\hline & & & & Infertility of both male and female origin & 81 & 13.30 \\
\hline & & & & I do not know & 325 & 53.30 \\
\hline
\end{tabular}

majority of men (54.3\%) would go to a gynecologist for a first consultation and the majority of these men (58.3\%) would go to a urologist for a second opinion with also more than a third (35.0\%) who would go to a second gynecologist for a second opinion. A lower proportion of men (42.5\%) would go to a urologist for a first opinion (cf. Fig. 1).

Knowledge of the causes and generalities about infertility According to the population studied, couple infertility is mainly due to clogged uterine horns (80.9\%), abnormal menstruations (ovulation problems) (79.5\%), and a history of infection of the male or female genital tract (64.1\% and 54.3\% respectively). Chronic diseases (55.8\%), obesity (53.5\%), and smoking (53.3\%) were also mentioned by most of the respondents. History of contraceptive pill use in women (34.5\%), IUD use (33.2\%), family pressures (26.4\%), regular exercise (sports activity) (13.9\%), supernatural causes (12.0\%), and black magic (2.4\%) are also causes of infertility cited by the respondents to the questionnaire (see Fig. 2).

An overwhelming majority think that infertility should be medically treated $(93.9 \%)$ and that it is socially acceptable to have medical treatment for fertility (92.3\%) but only $52.5 \%$ think that infertility is a disease. Most respondents would use IVF if they were infertile (87.5\%), think that it is socially acceptable to use IVF $(82.8 \%)$ and would adopt a child if they were infertile (70.8\%). More

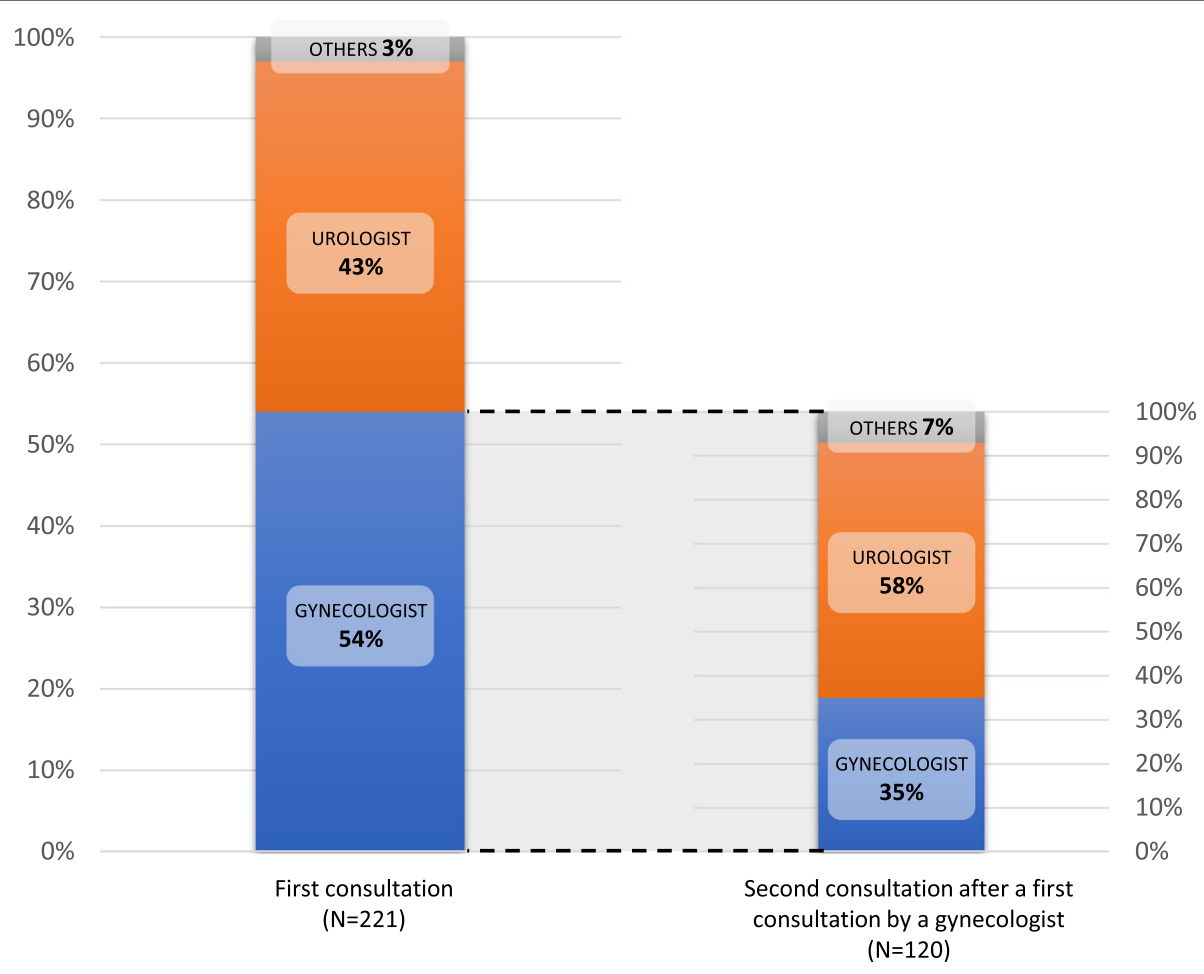

Fig. 1 Who would you go to for first and second consultations (male respondents) 


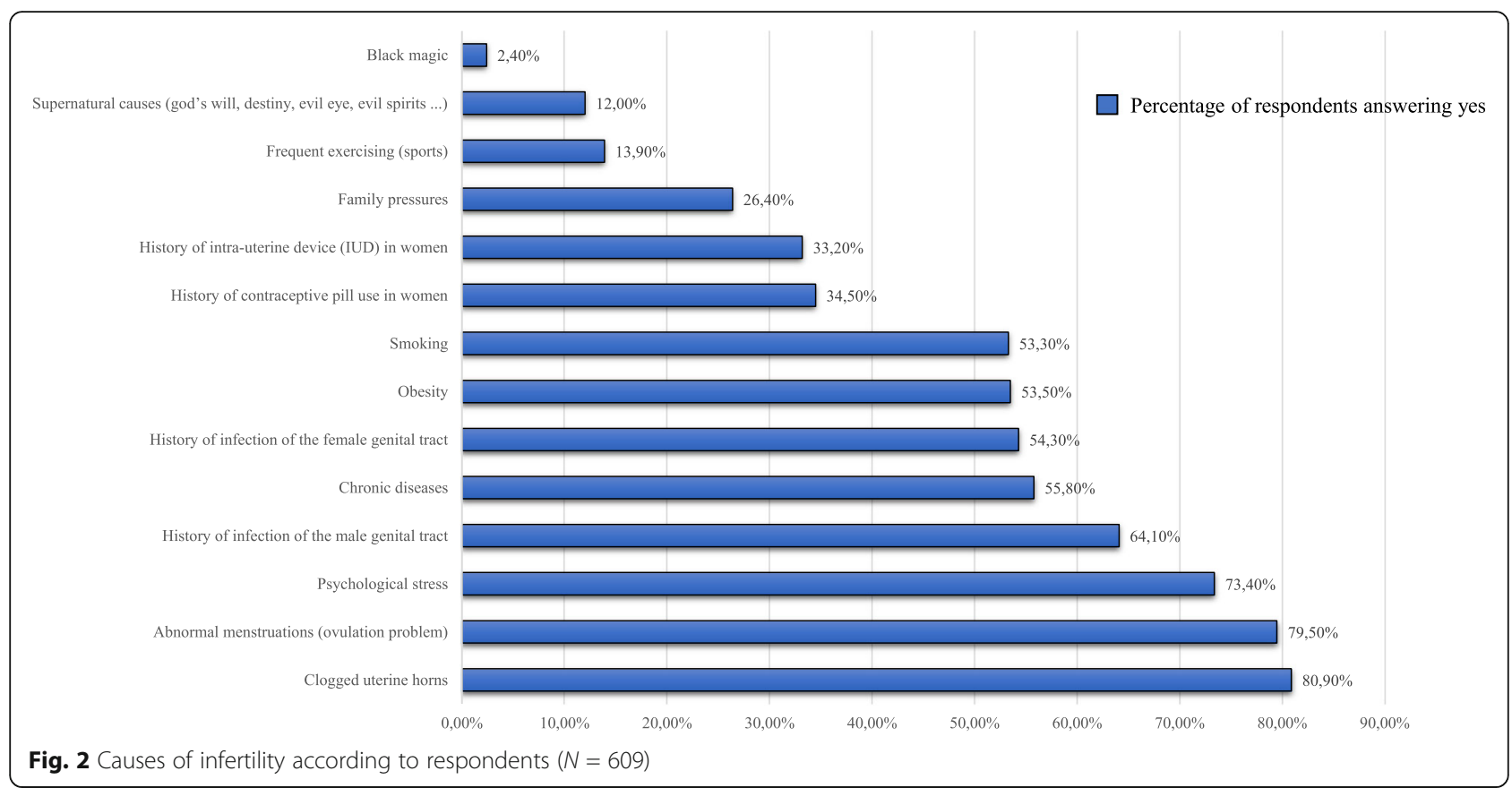

than half of the respondents also think that it is acceptable according to their religion to use IVF (66.2\%). A minority believe that the risk of testicular cancer is greater in infertile men (27.8\%), that if a woman or a man cannot have children, this would be a valid reason for a second marriage or divorcing a man $(9.7 \%)$ or a woman $(11.3 \%)$ or that an infertile man is less virile than a fertile man (4.8\%). A small proportion of respondents to the questionnaire feel that they are well informed about infertility (37.6\%) (cf. Fig. 3).

\section{Correlations with causes of infertility}

Half of the respondents who did not obtain their baccalaureate believed that supernatural causes could be the cause of infertility, compared to a lower proportion of

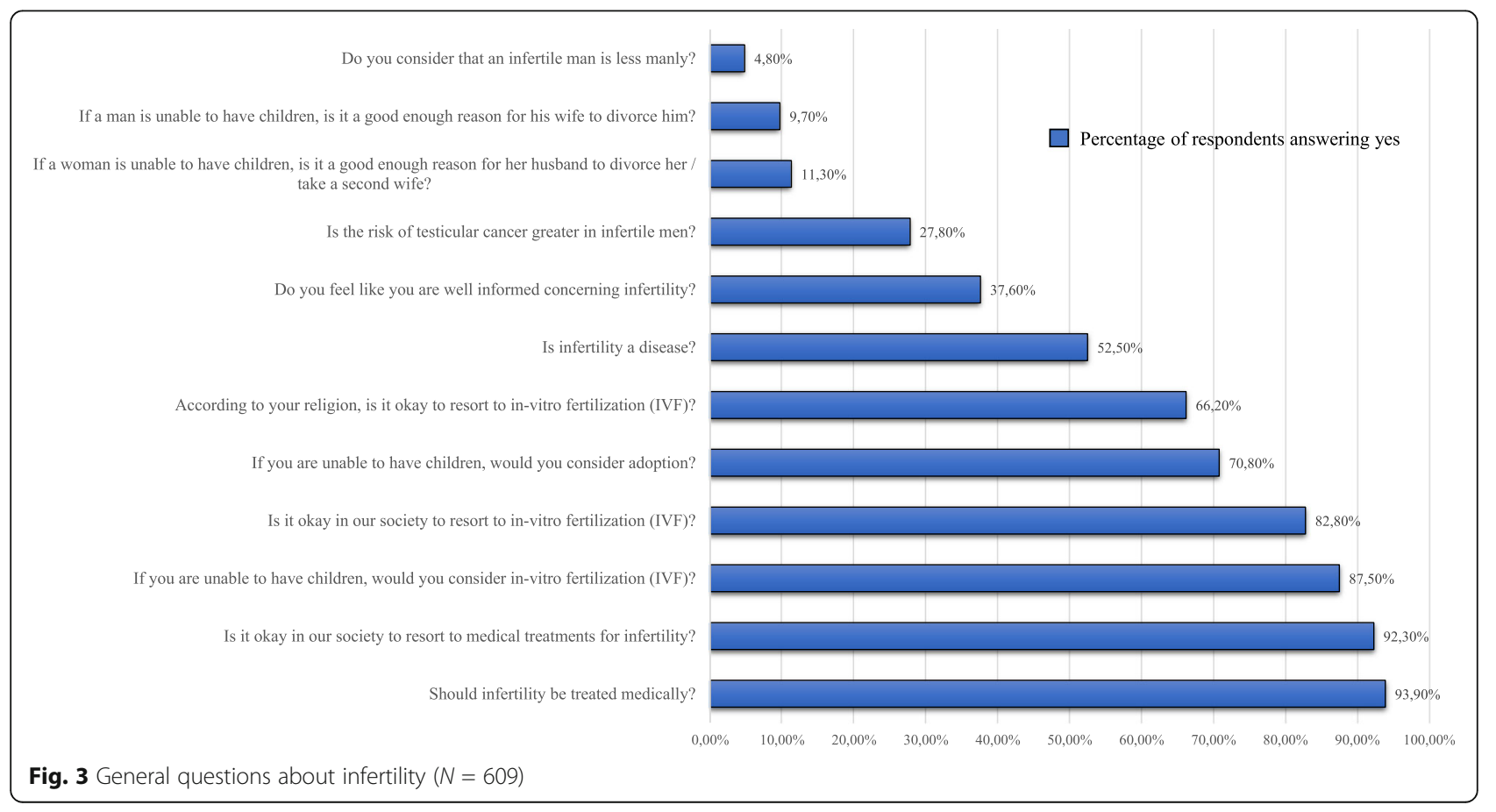


those who obtained their baccalaureate $(19.2 \%)$ or who had done university studies $(10.7 \%)$ ( $p$ value $=0.002$ ).

A minority of men who responded to the questionnaire think that supernatural causes can be the cause of infertility (6.5\%) compared to almost the double among women $(15.2 \%)$ ( $p$ value $=0.002)$.

More than a third of respondents aged 18 to 22 (36.4\%) think that family pressures are sometimes the cause of infertility compared to almost a quarter of those aged 23 to $44(23.2 \%)$ and a lower proportion among those aged 45 to $75(18.0 \%)$ ( $p$ value $=0.044)$.

More than two thirds of respondents aged 18 to 22 (67.1\%) think that chronic diseases are responsible for infertility, compared with lesser proportions among those aged 23 to $32(54.28 \%)$, aged 33 to 44 (46.8\%), and 45 to 75 years $(38.0 \%)$ ( $p$ value $=0.005)$.

\section{Infertility questions}

A higher proportion of men than women $(14.0 \%$ compared to $7.2 \%)$ think that if a man cannot have children, this would constitute a valid reason for a divorce ( $p$ value 0.006$)$. Also, more men than women (15.8\% versus $8.8 \%$, respectively) think that if a woman cannot have children, this would constitute a valid reason for a divorce or a second marriage ( $p$ value 0.008 ).

Most respondents with no school diploma think that if a woman cannot have children, this would constitute a valid reason for a divorce or a second marriage (66.7\%), while only one third of the respondents who did not obtain their baccalaureate thinks this (36.4\%). A minority of respondents having obtained their baccalaureate $(11.5 \%)$ or having studied at university (10.5\%) are of the same opinion ( $p$ value $=0.001)$. Respondents therefore believe less and less that a divorce or a second marriage is justified if the woman is infertile according to their academic level.

A minority of respondents who obtained their certificate or no school diploma (42.8\%) think that adoption is an option in the event of infertility against a majority of respondents who obtained their baccalaureate $(53.8 \%)$ or who have done university studies $(72.2 \%)$ ( $p$ value $=0.023)$. Adoption is therefore considered more and more socially acceptable according to the academic level of the respondents.

Most respondents without a school diploma (66.7\%) think that an infertile man is less virile, compared to only a minority of respondents who have obtained a school diploma $(2.7 \%)$ or have studied at university $(4.6 \%)(p$ value $=0.022)$. Respondents without a school diploma are therefore much more likely to consider that an infertile man is also less virile.

\section{Discussion}

\section{Demographic data}

The survey respondents were predominantly female, with men less likely to complete the questionnaire. This can be explained by the fact that Lebanese men feel that infertility does not concern them. Indeed, a common misconception is that infertility mainly affects women. This results are consistent with a study of 447 participants in Pakistan, 55\% of whom were women [7], and a study of 272 participants in Indonesia of whom 56.9\% were women [6].

\section{Knowledge of infertility's causes and the generalities surrounding it}

About $10 \%$ of the questionnaire respondents claimed to have already experienced a period of infertility. However, $13.8 \%$ of them said they have tried to have a child for less than a year. As infertility is defined, these respondents are not considered infertile. This implies that the exact definition of infertility is still rather vague for the general population. This finding is in line with an international study carried out on 8194 participants, which showed that only 1 in 2 participants was able to, more or less correctly, define infertility [8] as specified by the World Health Organization [9]. On the other hand, the respondents correctly estimated the prevalence of infertility, which is about $15 \%$ according to the latest studies, one of which is a prospective study conducted by Thoma et al. in the USA [1].

More than half of the respondents (52.0\%) believe that according to Lebanese society, women are most often blamed when a couple is infertile. This trend is much more evident in the study from Pakistan, in which $86 \%$ of the respondents said they believed that Pakistani society primarily blamed women for infertility [7].

Our results also show that most respondents would first consult a gynecologist before considering seeing a urologist. This may be a logical choice for women, but the remarkable fact is that more than half of the men $(54.0 \%)$ would also consult a gynecologist first and only go to a urologist for a second opinion. This data is in line with the Pakistani study, which showed that $72 \%$ of the participants would first visit a gynecologist [7]. However, because of their socio-cultural beliefs and habits, $75 \%$ of the Pakistani participants responded that they would seek second-line treatment at practitioners of alternative medicine (homeopaths) or even spiritual healers or hakeems. The belief that both the man and the woman should go to the gynecologist when the couple is infertile probably originates from a societal tendency to blame women first for uninvestigated couple infertility. Another explanation could be a lack of awareness about the role of urologists or the fact that gynecologists do not refer their infertile patients to urologists for multidisciplinary management. Further research is needed to investigate how often and why gynecologists choose not to refer infertile couples to urologists. 
Most respondents identified correctly the different possible causes of infertility. However, there is still a significant percentage of respondents $(12.0 \%)$ who consider supernatural causes such as God's will, fate, the evil eye, evil spirits, and black magic as potential causes of infertility. However, the percentage is far less than the figures published in the Pakistani study, which showed that about a third of respondents believed supernatural causes and black magic to be causes of infertility [7]. The discrepancy between the Lebanese and Pakistani responses could be attributed to the socio-cultural beliefs and habits of the two populations. Furthermore, a study conducted in Indonesia showed that more than half of the participants from East Sumba believed supernatural events could be the cause of infertility versus only a minority in Jakarta [6].

Our study found that in vitro fertilization is a more desired alternative than adoption as a solution to infertility, while the Pakistani study found that more than $90 \%$ of participants would consider adoption versus only $45 \%$ who would use IVF [7]. In Indonesia, both adoption and in vitro fertilization were deemed acceptable solutions to infertility (about 83\% for adoption and 82\% for IVF in Jakarta versus 84\% for adoption and 75\% for IVF in East Sumba) [6].

\section{Correlations with causes of infertility}

There is an inversely proportional relationship between the education level of respondents and their belief in supernatural reasons for infertility. This relationship is also found in the Pakistani study and can be explained by the fact that the less educated are more inclined to attribute their infertility to a demonic or supernatural force which cannot be controlled by humans, or a belief in the will of God, among other beliefs [7]. This tendency was also found in a study conducted among $\mathrm{Ku}$ waiti women [10]. The Kuwaiti survey also showed that women were twice as likely to believe in supernatural powers as men, who tended to choose scientific and rational causes for infertility in the survey.

Family pressures have already been shown to play a significant role in infertility, particularly in men, who can present erectile dysfunction due to family pressures which induce stress, depression, and sometimes psychological infertility [11]. It is interesting to note that the number of respondents who consider these pressures to affect conception decreases with respondent age. This can be explained by the fact that in Lebanese society, younger people are victims of pressure from their elders, who do not consider their insistence and incessant interventions into the married life of their children as possible causes of infertility.

Note that no correlations were found between the civil status and the profession of the participants with any of their responses to the questionnaire.

\section{Infertility questions}

There is a clear difference between the rate of men and women who think that infertility is a valid reason for a divorce or a second marriage. Indeed, twice as many men would refuse to live with an infertile spouse $(15.8 \%$ of men versus $7.2 \%$ of women). This can be explained by the fact that in Lebanese society, divorce and/or a second marriage is simpler for men because of the lack of civil personal status law and women rights, or by a lack of education concerning means of medically assisted procreation. The Pakistani study showed that $57 \%$ of participants favored a second marriage if the woman was infertile, compared to $41 \%$ of participants who favored a divorce if the man was infertile [7]. The authors of this study explain this by the fact that the blame for infertility is very often placed on the woman and that it is easy for the male participants to marry a second time due to religious reasons. In addition, Lebanese society has a negative perception of divorced women, but not of divorced men. This trend can also be found in Egypt and many other Arab countries, where women who cannot have children are considered "incomplete women" [4]. Furthermore, the relatives of the infertile couple often try to interfere, as is the case in Iran, where infertile couples were encouraged to divorce or remarry $(77.3 \%$ and $86.9 \%$, respectively) versus a minority of fertile couples (22.7\% and $13.2 \%$, respectively) [12].

Likewise, there is also a statistically significant relationship between the age of the respondents and their belief that IVF is socially acceptable in their religion. The majority of Pakistani participants replied that IVF would be unacceptable according to their religion (almost $95 \%$ of the participants were Muslim) [7]. The authors of this study explain this by the fact that the participants are poorly informed about the technique of IVF: indeed, Islam allows couples to use this technique provided there is no third-party involvement [13]. Indeed, in Lebanon, as stated in a previous study about assisted reproduction techniques, only married couples can resort to assisted fertility techniques or artificial insemination [5]. The higher acceptance of IVF by older respondents can also be attributed to the fact that, the older you are, the higher the probability is that you or someone you know has experienced IVF without having been subjected to pressures from religious authorities.

Our results showed that education level is correlated with the positive perception regarding adoption. Indeed, the most educated tended to be more aware and open to the idea of adopting or undergoing IVF. As noted above, the Pakistani study found that Pakistani respondents were also very open to the idea of adopting a child in the event of couple infertility [7]. However, this tendency is not present in all of the Arab world as adoption is prohibited in Muslim Sunni countries by religious 
mandates whereas Shi'ite countries and Lebanon are open to adoption and gamete donations [14]. Indonesian respondents in both East Sumba and Jakarta were in favor of adoption as a solution for infertile couples [6]. Also, in our study, the respondents who did not graduate from high school were very inclined to consider an infertile man less virile. This is explained by the fact that these participants have difficulties in distinguishing between virility and fertility, two independent concepts.

After conducting this study, it became obvious that multiple measures should be implemented in order to provide better care for infertile couples in Lebanon. First, awareness campaigns should be conducted on a national level, tackling the subjects least familiar to the population; these include male causes of infertility, the shared responsibility of couple infertility, and the availability of medical solutions to overcome infertility. Second, a day could be dedicated every year to raise awareness about infertility, as is the case for many other medical issues, such as World Tobacco Day; national infertility societies should be the ones leading the charge. Messages could be broadcast on TV, radio, social media, or via video conferences. Third, it is crucial to adopt a multidisciplinary approach that includes all fertility specialists when treating cases of couple infertility. Finally, because infertility is considered a disease by the World Health Organization, it should be considered and treated as such in every country. As a matter of fact, coverage for the treatment of infertile patients is still not provided by third-party payers in Lebanon.

\section{Limitations}

The participants in this study were healthy individuals as well as patients at an infertility clinic. However, the statistical analysis did not take these factors into account and the responses were analyzed only according to the sex, age, academic level, profession, and marital status of the participants. Future studies could examine how personal experience of infertility affects knowledge and perceptions of infertility.

In addition, the majority of our respondents were university students. This study is cross-sectional by nature; therefore, no causality assessment can be derived from the current results. Since the survey is based on convenience sampling, the results cannot be generalized to the Lebanese population and do not reflect the Lebanese culture as a whole, a common limitation encountered in studies of this kind. No studies are available in the Middle East, so there are no means to check whether the results found in the current study can be generalized to the Middle Eastern population. Since it is crosssectional, the study cannot assess the temporal trend of the main results. It would be interesting to reconduct a survey in the near future to assess if the cultural attitudes are stable.

\section{Conclusion}

The general population remains poorly educated and unaware of the exact definition, causes, and consequences of infertility. Indeed, certain preconceptions and supernatural beliefs sometimes take precedence over logical and rational reasoning, especially among people from lower educational backgrounds. In addition, women in our society are often blamed for infertility, and this trend has not changed despite the development of screening techniques and examinations for men. As a result, gynecologists are consulted in the majority of first- and second- line treatment at the expense of other fertility experts such as urologists who are rarely consulted for second-line treatment despite a high prevalence of male infertility. Finally, more men think infertility is a valid reason for divorce, regardless of who in the couple is infertile.

Therefore, awareness campaigns must be put in place to rectify existing ideas and establish a scientific understanding of infertility in Lebanon.

\section{Acknowledgements \\ Not applicable}

\section{Authors' contributions}

$\mathrm{EH}$ and JPS wrote the manuscript and established the research plan. GS analyzed and interpreted the patient data regarding their answers of the questionnaire. JA, LS, and IAJ helped in the diffusion of the questionnaire. All authors read and approved the final manuscript.

Funding

None

Availability of data and materials

The datasets used and/or analyzed during the current study available from the corresponding author on reasonable request.

Ethics approval and consent to participate

Approved by the ethics committee of Hôtel-Dieu de France Hospital. Consent to participate was in written form.

Ethics committee reference number: Tfem-2019-75

Consent for publication

Not applicable

\section{Competing interests}

The authors declare that they have no competing interests.

\section{Author details}

${ }^{1}$ Hôtel-Dieu de France Hospital, Faculty of Medicine, Saint-Joseph University, Beirut, Lebanon. 'Urology Department at Hôtel-Dieu de France Hospital, Faculty of Medicine, Saint-Joseph University, Beirut, Lebanon. ${ }^{3}$ IVF Center at Mont-Liban Hospital, Beirut, Lebanon. ${ }^{4}$ OB-GYN Department, IVF Center at Abou Jaoude Hospital, Beirut, Lebanon. ${ }^{5}$ Clinical Research Center at Hôtel-Dieu de France Hospital, Faculty of Medicine, Saint-Joseph University, Beirut, Lebanon. 
Received: 8 May 2020 Accepted: 30 July 2020

Published online: 10 September 2020

\section{References}

1. Thoma ME, MCLain AC, Louis JF, King RB, Trumble AC, Sundaram R et al (2013) Prevalence of infertility in the United States as estimated by the current duration approach and a traditional constructed approach. Fertil Steril 99(5):1324-1331.e1

2. (2013) Definitions of infertility and recurrent pregnancy loss: a committee opinion. Fertil Steril 99(1):63

3. Alimohamadi Y, Mehri A, Sepandi M, Esmaeilzadeh F, Rashti R (2020) The prevalence of depression among Iranian infertile couples: an update systematic review and meta-analysis. Middle East Fertil Soc J 25(1):16

4. Zayed AA, El-Hadidy MA (2020) Sexual satisfaction and self-esteem in women with primary infertility. Middle East Fertil Soc J 25(1):13

5. Kooli C (2019) Review of assisted reproduction techniques, laws, and regulations in Muslim countries. Middle East Fertil Soc J 24(1):8

6. Harzif AK, Santawi VPA, Wijaya S. Discrepancy in perception of infertility and attitude towards treatment options: Indonesian urban and rural area. Reprod Health. 2019 [cited 2020 Jul 5];16. Available from: https://www.ncbi. nlm.nih.gov/pmc/articles/PMC6700767/

7. Ali S, Sophie R, Imam AM, Khan Fl, Ali SF, Shaikh A et al (2011) Knowledge, perceptions and myths regarding infertility among selected adult population in Pakistan: a cross-sectional study. BMC Public Health 11:760

8. Public perception on infertility and its treatment: an international survey. Hum Reprod. 2000;15(2):330-334.

9. (1992) Recent advances in medically assisted conception. Report of a WHO Scientific Group. World Health Organ Tech Rep Ser 820:1, 111

10. Fido A (2004) Emotional distress in infertile women in Kuwait. Int J Fertil Womens Med 49(1):24-28

11. BARSE KO. Infertilité \& stress. Guide de I'Infertilité. [cited 2020 Feb 3]. Available from: https://www.guide-de-l-infertilite.fr/fr//-infertilite-inexpliquee/ article/infertilite-stress

12. Amiri M, Khosravi A, Chaman R, Sadeghi Z, Raei M, Jahanitiji MA et al (2016) Social consequences of infertility on families in Iran. Global J Health Sci 8(5): 89-95

13. Inhorn MC (2006) Making Muslim babies: IVF and gamete donation in Sunni versus Shi'a Islam. Cult Med Psychiatry 30(4):427-450

14. Inhorn MC (2006) He won't be my son. Med Anthropol Q 20(1):94-120

\section{Publisher's Note}

Springer Nature remains neutral with regard to jurisdictional claims in published maps and institutional affiliations.

\section{Submit your manuscript to a SpringerOpen ${ }^{\circ}$ journal and benefit from:}

- Convenient online submission

- Rigorous peer review

- Open access: articles freely available online

- High visibility within the field

- Retaining the copyright to your article

Submit your next manuscript at $\boldsymbol{\nabla}$ springeropen.com 